\title{
Preparation and Characterization of Water Self-dispersible Poly(3-hexylthiophene) Particles
}

\author{
By Hidenobu SHIMIZU, ${ }^{1, *}$ Mamiko YAMADA, ${ }^{1}$ Risei WADA, ${ }^{1}$ and Masaru OKABE ${ }^{1}$
}

The present paper describes the preparation and characterization of stable aqueous dispersions of poly (3-hexylthiophene) (P3HT) by a precipitation method. P3HT was first synthesized by oxidative polymerization of 3HT with iron(III) chloride as an oxidant. Number-average molecular weight $\left(\bar{M}_{\mathrm{n}}\right)$ of P3HT increased with an increase in 3HT concentration. Colloidal particles were prepared by adding a tetrahydrofuran (THF) solution of P3HT into a large amount of distilled water. TEM observations showed that the particle size increased with an increase in the concentration and $\bar{M}_{\mathrm{n}}$ of P3HT. The size of the particles was in the range of 50 to $600 \mathrm{~nm}$. The spectral features of the aqueous dispersions were investigated by means of UV-vis spectroscopy. P3HT provided the $\pi-\pi^{*}$ absorption band at $436 \mathrm{~nm}$ in THF. On the other hand, the dispersions brought about a bathochromic shift of the bands and a larger red shift was observed as the polymer concentration became higher, indicating that P3HT would take a well-stacked structure in the particles. Temperature dependence of UV-vis absorption spectra for $\mathrm{P} 3 \mathrm{HT}$ aqueous dispersions was also studied in the temperature range of 0 to $80^{\circ} \mathrm{C}$, which revealed that $\mathrm{P} 3 \mathrm{HT}$ in the dispersed state showed a thermochromism similar to that of P3HT in THF.

KEY WORDS: Polythiophene / $\pi$-Conjugated Polymer / Poly(3-hexylthiophene) / Colloidal Particle / Conducting Polymer /

Precipitation Method / Thermochromism /

Poly(3-hexylthiophene) (P3HT) is a subject of extensive study because of its solubility, fusibility, and environmental stability. ${ }^{1}$ P3HT also exhibits unique properties such as thermochromism and solvatochromism. ${ }^{2-6}$ This functional polymer is viewed as potentially useful materials in fieldeffect transistors, optical and electronic sensors, light-emitting devices, nonlinear optical materials, etc. ${ }^{7-9}$

Our attention has focused on colloidal dispersions of P3HT particles. Colloidal particles are of great importance due to their interesting physical properties as well as their potential technological applications. ${ }^{10,11}$ Several attempts have been made so far to produce P3HT particles. Yamamoto et al. employed a reprecipitation method to prepare colloidal dispersions of P3HT. Methanol, which is a poor solvent for $\mathrm{P} 3 \mathrm{HT}$, was added to the $\mathrm{CHCl}_{3}$ solution of P3HT, resulting in the formation of P3HT particles. ${ }^{12,13}$ Takeuchi and Kobashi also investigated in detail the kinds of poor solvents and clarified the precipitation conditions for improved yields. ${ }^{14}$ Furthermore, it has been reported that the use of a nonionic surfactant, Tween 80 , provided stable aqueous dispersions of P3HT. ${ }^{15}$

To our knowledge, few reports on water self-dispersible P3HT particles have been published. ${ }^{15}$ There is hence a lack of information about colloidal properties of P3HT water dispersions, such as particle size, particle morphology, optical property, etc. Development and characterization of such dispersions are of great significance from an environmental as well as industrial aspect. The purpose of the present study is to develope self-dispersible P3HT particles in aqueous media by a reprecipitation method. The particle size and the optical property of the colloidal dispersions are discussed as a function of polymer concentration and molecular weight.

\section{EXPERIMENTAL}

\section{Materials}

3-Hexylthiophene (3HT, Aldrich Chemical Co.) and iron (III) chloride $\left(\mathrm{FeCl}_{3}\right.$, Kanto Chemical Co.) were used as received. All other chemicals were of analytical grade unless specified otherwise.

\section{Polymerization of $\mathbf{3 H T}$}

P3HT was synthesized by chemical oxidative polymerization of $3 \mathrm{HT}$ in chloroform with $\mathrm{FeCl}_{3}$ as an oxidant. ${ }^{16}$ The polymerization was carried out under a $\mathrm{N}_{2}$ atmosphere at room temperature for $12 \mathrm{~h}$ and then the reactants were poured into a mixture of concentrated hydrochloric acid and methanol $(5 / 95, \mathrm{v} / \mathrm{v})$. The black precipitates were collected on a Buchner funnel, purified by Soxhlet extraction with methanol, and finally dried under reduced pressure.

\section{Preparation of Colloidal P3HT Particles}

Colloidal P3HT particles were obtained by a reprecipitation method. A THF solution of P3HT was prepared at various concentrations ranging from 0.01 to $3.0 \mathrm{wt} \%$. The polymer solution $(1.0 \mathrm{~mL})$ was then added into distilled water of $50 \mathrm{~mL}$. The water was gently stirred in a vial at given temperature.

\section{Characterization}

The number-average molecular weight $\left(\bar{M}_{\mathrm{n}}\right)$ and the index

\footnotetext{
${ }^{1}$ Department of Applied Chemistry, Faculty of Engineering, Kanagawa Institute of Technology, 1030 Shimo-ogino, Atsugi 243-0292, Japan

*To whom correspondence should be addressed (Tel \& Fax: +81-46-291-3148, E-mail: shimizu@ chem.kanagawa-it.ac.jp).
} 
of molecular weight distribution $\left(\bar{M}_{\mathrm{w}} / \bar{M}_{\mathrm{n}}\right)$ were determined by size exclusion chromatography (SEC, Shodex GPC-101) equipped with high resolution columns (Shodex K-806M×2). Eluent solvent was HPLC grade chloroform with a flow rate of $1 \mathrm{~mL} / \mathrm{min}$. Polystyrene standards were used for calibration.

The size and morphology of P3HT particles were observed by means of transmission electron microscopy (TEM) (JEOL EX-2000). Small amounts of the particle dispersions were infinitely diluted with distilled water. The diluted samples were applied on collodion-coated $\mathrm{Cu}$ grids to prepare TEM samples.

All UV-vis spectra were taken on the aqueous dispersions of P3HT with a Shimadzu UV-1600 spectrophotometer.

\section{RESULTS AND DISCUSSION}

\section{Chemical Synthesis of P3HT}

The synthesis of P3HT was carried out by chemical oxidation of $3 \mathrm{HT}$ with $\mathrm{FeCl}_{3}$ as an oxidant. The oxidant was kept constant in a molar ratio 4:1 with respect to 3 HT. The molecular weight and the distribution of P3HT were analyzed by means of SEC. Table I summarized the molecular characteristics of P3HT synthesized. The number-average molecular weight $\left(\bar{M}_{\mathrm{n}}\right)$ increased with an increase in $3 \mathrm{HT}$ concentrations in the feed. These results indicate that $\bar{M}_{\mathrm{n}}$ of P3HT can be controlled over a wide range of $0.4 \times 10^{4}$ to $7.0 \times 10^{4}$ by varying $3 \mathrm{HT}$ concentrations. In addition, polydispersities of all P3HT synthesized here were below 2.0, suggesting that P3HT with relatively narrow molecular weight distribution can be obtained by using chemical oxidation of $3 \mathrm{HT}$ with $\mathrm{FeCl}_{3}$. Polymer samples are referred to as P3HT-Z, where $\mathrm{Z} \times 10^{4}$ is the molecular weight of P3HT synthesized.

\section{Particle Size and Morphology}

P3HT has good solubility in $\mathrm{CHCl}_{3}$ and THF, but it is insoluble in dimethylformamide, methanol, and water. ${ }^{12}$ Addition of P3HT in good solvent into non-solvent, therefore, affords precipitation of P3HT chains from the solution, followed by aggregation of the precipitated chains. Stable (mature) colloidal dispersions could be obtained provided these aggregates have electrostatic or steric stability. This approach is called a reprecipitation method, which is a simple and useful technique for obtaining liquid dispersions of organic crystals and polymer. ${ }^{17,18}$

In the present study, a reprecipitation method mentioned above was used to obtain self-dispersible P3HT colloidal

Table I. Influence of polymerization conditions on molecular weights of $\mathrm{P} 3 \mathrm{HT}$

\begin{tabular}{ccccccccc}
\hline Code & $\begin{array}{c}{[3 \mathrm{HT}]} \\
(\mathrm{mol} / \mathrm{L})\end{array}$ & $\begin{array}{c}3 \mathrm{HT} \\
(\mathrm{g})\end{array}$ & $\begin{array}{c}\mathrm{FeCl}_{3} \\
(\mathrm{~g})\end{array}$ & $\begin{array}{c}\mathrm{CHCl}_{3} \\
(\mathrm{~g})\end{array}$ & $\begin{array}{c}\mathrm{Temp} . \\
\left({ }^{\circ} \mathrm{C}\right)\end{array}$ & $\begin{array}{c}\text { Yield } \\
(\%)\end{array}$ & $\bar{M}_{\mathrm{n}} \times 10^{-4 \mathrm{a}}$ & $\bar{M}_{\mathrm{w}} / \bar{M}_{\mathrm{n}}{ }^{\mathrm{a}}$ \\
\hline P3HT-0.4 & 0.050 & 0.34 & 1.30 & 44.2 & 25 & 14.1 & 0.37 & 1.79 \\
P3HT-3.3 & 0.068 & 0.46 & 1.74 & 44.2 & 25 & 13.7 & 3.32 & 1.73 \\
P3HT-5.2 & 0.100 & 0.34 & 1.30 & 22.1 & 25 & 49.8 & 5.18 & 1.83 \\
P3HT-6.8 & 0.200 & 0.68 & 2.60 & 22.1 & 25 & 68.1 & 6.83 & 1.95 \\
P3HT-6.9 & 0.400 & 1.36 & 5.20 & 22.1 & 25 & 11.0 & 6.91 & 1.29 \\
\hline
\end{tabular}

a Determined by SEC particles. Distilled water was also utilized as a disperse medium from an environmental point of view. P3HT water dispersions were prepared by adding a THF solution of P3HT into a large number of distilled water at varying polymer concentrations in THF. The stable and self-dispersible aqueous dispersions were obtained in the concentration range of 0.1 to $2.5 \mathrm{wt} \%$ and then these dispersions were stable at least for 6 months on standing. At higher concentrations above $2.5 \mathrm{wt} \%$, however, macroscopic precipitates were formed on the water surface as soon as the polymer solution was added. The mechanism of colloidal stability for self-dispersible particles remains unclear, but electrophoretic mobility studies in an aqueous solution of $0.01 \mathrm{M} \mathrm{KCl}$ showed that P3HT particles have a negative charge and thus chloride ion adsorbed on the particles, which ion originate from $\mathrm{FeCl}_{3}$ during polymerization, may contribute to the colloidal stability.

The particle size and morphology of P3HT particles were investigated as a function of polymer concentrations by means of TEM. Figure 1 describes the results of P3HT- 6.8 particles. All particles were almost spherical, but the size distribution was relatively broad. Figure 2 summarizes the effect of polymer concentration and molecular weight on particle size. Increase in the average particle size was observed independent of $\bar{M}_{\mathrm{n}}$ as P3HT concentrations increased. The size increased somewhat steeply at the concentration of about $0.75 \mathrm{wt} \%$. These results are probably due to an increase in the number of precipitated polymer chains as $\mathrm{P} 3 \mathrm{HT}$ concentrations became higher. In addition, increased $\bar{M}_{\mathrm{n}}$ led to production of a larger particle size. Although several researchers reported the

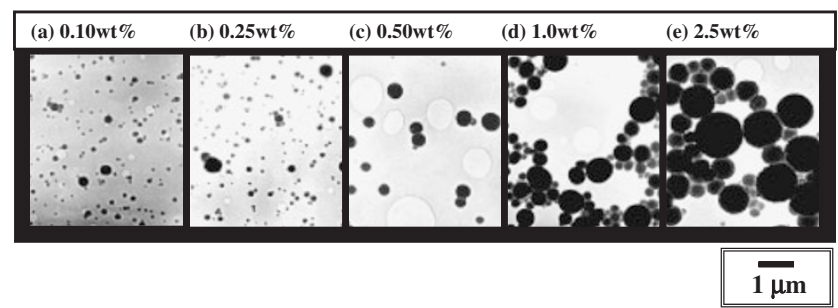

Figure 1. TEM images of $\mathrm{P} 3 \mathrm{HT}-6.8$ particles prepared at different $\mathrm{P} 3 \mathrm{HT}$ concentrations.

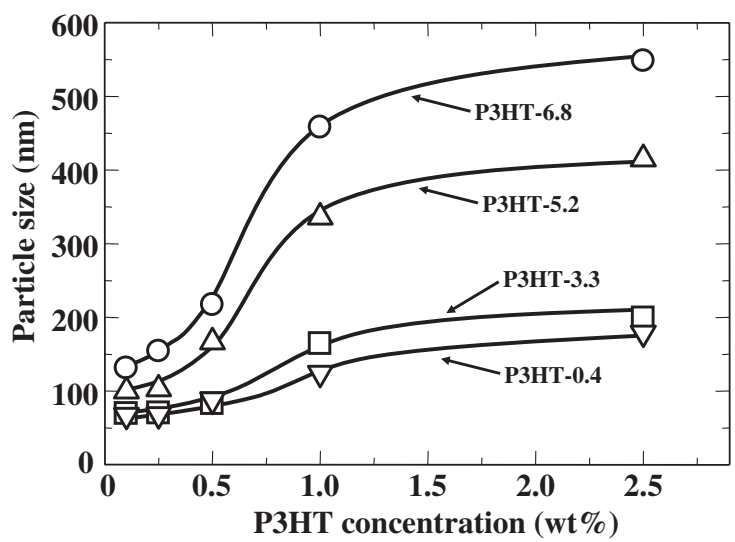

Figure 2. Effect of $\mathrm{P} 3 \mathrm{HT}$ concentration and molecular weight on particle size. 


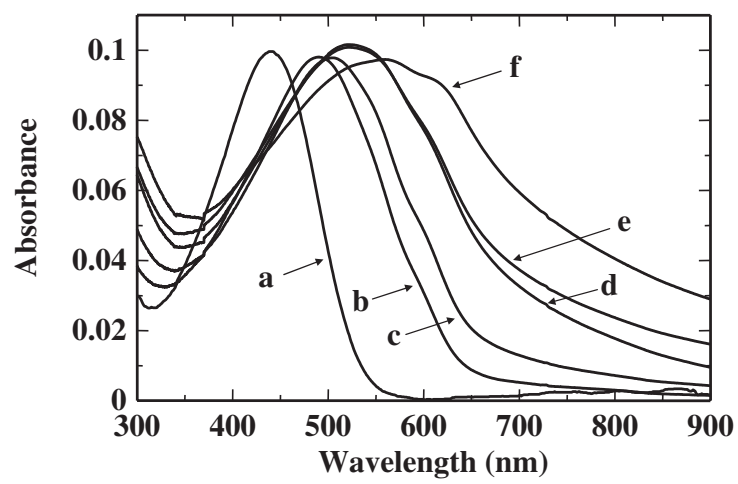

Figure 3. Optical absorption spectra of (a) P3HT THF solution, and colloidal P3HT-6.8 particles prepared at the concentration of (b) $0.10 \mathrm{wt} \%$, (c) $0.25 \mathrm{wt} \%$, (d) $0.50 \mathrm{wt} \%$, (e) $1.0 \mathrm{wt} \%$, and (f) $2.5 \mathrm{wt} \%$.

preparation of P3HT colloidal dispersions in various solvents, the resulting average hydrodynamic size with dynamic light scattering was limited in the range below $100 \mathrm{~nm} .{ }^{12-14}$ On the other hand, the present study demonstrated that the average size of P3HT particles can be controlled in the range of 50 to $600 \mathrm{~nm}$ by varying polymer concentrations and molecular weights.

\section{Spectroscopic Properties}

Figure 3 exhibits UV-vis spectra of the colloidal dispersions of P3HT-6.8 as a function of polymer concentrations. P3HT dissolved in THF provided the $\pi-\pi^{*}$ absorption band at $436 \mathrm{~nm}$. On the other hand, P3HT dispersions prepared at the concentration of $0.1 \mathrm{wt} \%$ had a similar spectral shape, but showed a red shift of the peak. Furthermore, a shoulder peak appeared around $600 \mathrm{~nm}$, which can be assigned to vibronic structure with a $0-0$ transition $\left(\pi-\pi^{*}\right.$ transition originated from $\pi$ electron orbital overlap between adjacent thiophene rings). 2,19 Such a spectral profile is in agreement with that of P3HT colloidal dispersions in various solvents, ${ }^{12-15}$ indicating that $\pi-$ stacking interaction caused by aggregation of polymer chains would take place in the particle. Figure 3 also shows that the increased polymer concentrations led to a larger red shift and a broader spectrum, suggesting that interchain interaction would be stronger as the concentration became higher. This is the first report on P3HT colloidal particles with different spectral profiles as far as we know.

Next we examined the effect of $\bar{M}_{\mathrm{n}}$ on optical properties. The results at the polymer concentration of $0.5 \mathrm{wt} \%$ are shown in Figure 4. Spectra were little affected by $\bar{M}_{\mathrm{n}}$ except for the lowest $\bar{M}_{\mathrm{n}}$ in the present study, whereas the particle size increased from 80 to $220 \mathrm{~nm}$ with an increase in $\bar{M}_{\mathrm{n}}$. The fact that there was little difference in the spectra of the colloidal dispersions at different sizes suggests that an aggregation state of P3HT chains in particles would be mainly determined by not $\bar{M}_{\mathrm{n}}$ and size but polymer concentration at particle formation. In summary, an increase in the number of precipitated polymer chains at higher concentrations leads to stacking of polymer chains. The $\pi$-stacking in colloidal particles would cause an absorption band at longer wavelengths.

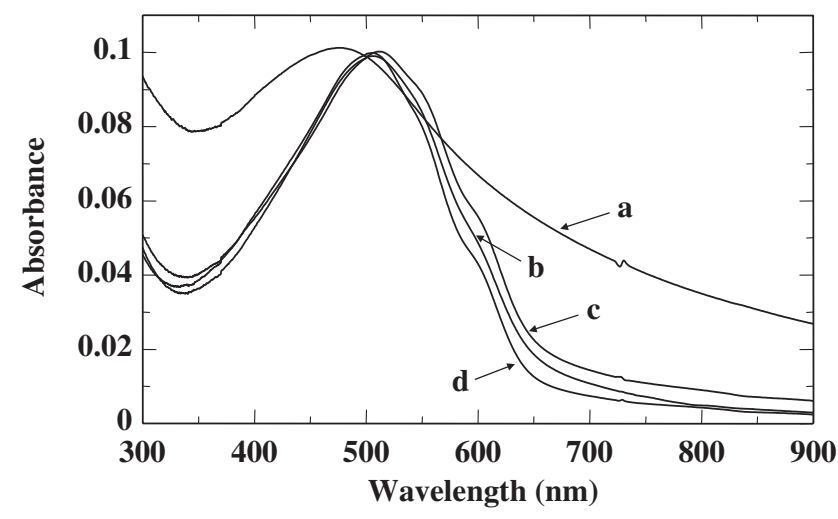

Figure 4. Optical absorption spectra of colloidal particles of (a) P3HT-0.4, (b) P3HT-3.3, (c) P3HT-5.2, and (d) P3HT-6.8. The particles were prepared at the concentration of $0.50 \mathrm{wt} \%$.

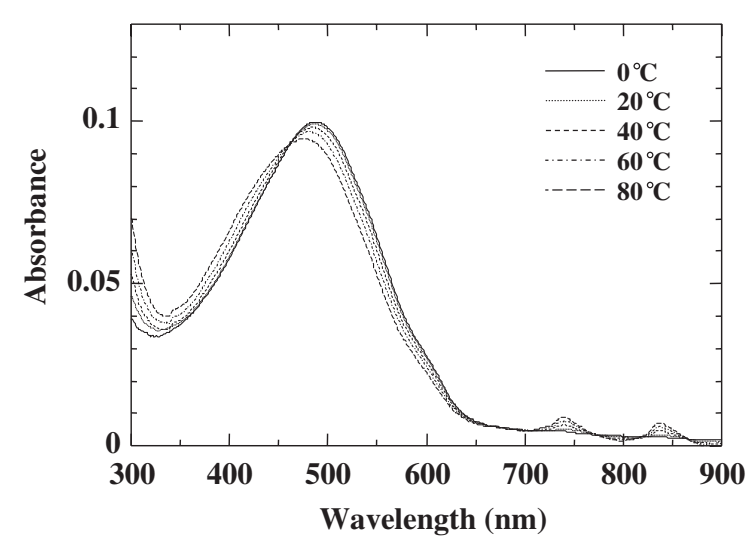

Figure 5. Temperature dependence of UV-vis absorption spectra of P3HT6.8 colloidal particles prepared at the concentration of $0.25 \mathrm{wt} \%$.

\section{Thermochromism}

Figure 5 shows temperature dependence of UV-vis absorption spectra of $\mathrm{P} 3 \mathrm{HT}$ in the water dispersion state. The spectra were recorded at $20^{\circ} \mathrm{C}$ intervals between 0 and $80^{\circ} \mathrm{C}$. P3HT-6.8 particles prepared at the concentration of $0.25 \mathrm{wt} \%$ were used in this experiment. At $0{ }^{\circ} \mathrm{C}$ an absorption maximum around $487 \mathrm{~nm}$ was observed. Upon heating, the absorption peak shifted to a shorter wavelength and also the absorbance of the peak slightly decreased. In addition, two new peaks appeared near 740 and $840 \mathrm{~nm}$ and the intensity of these peaks increased with an increase in temperature. These bands have not been assigned yet. An internal particle structure should be investigated as a function of temperature to assign them. This thermochromic behavior was reversible. Figure 6 summarizes an absorption maximum of P3HT colloidal dispersions in water and P3HT solution in THF as a function of temperature. Two samples with different molecular states exhibited similar behavior, indicating that a transition from ordered phase to quasi-ordered phase in particles would take place upon heating.., 20

\section{CONCLUSIONS}

Preparation and characterization of water self-dispersible 


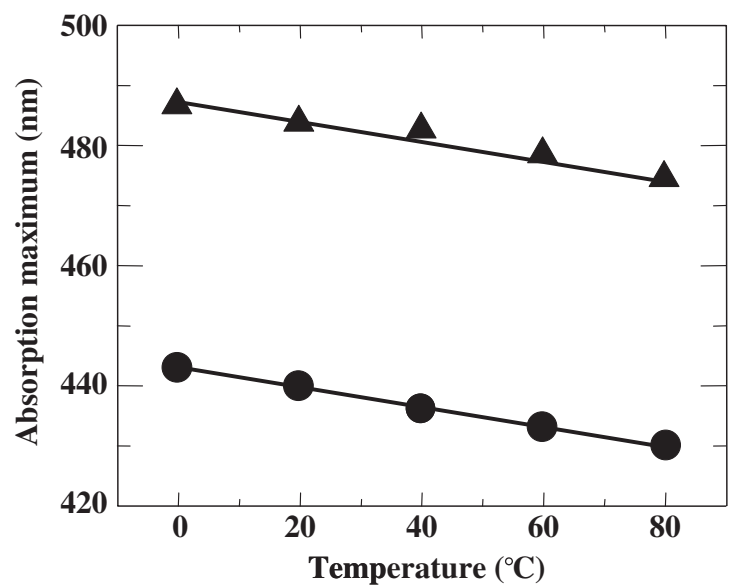

Figure 6. Temperature dependence of absorption maximum for $\mathrm{P} 3 \mathrm{HT}$ colloidal dispersions in water $(\mathbf{\Delta})$ and P3HT solution in THF $(\mathbf{O})$

P3HT particles with a precipitation method leads to the following conclusions:

1. Stable aqueous dispersions of P3HT can be obtained by adding a THF solution of P3HT into a large amount of distilled water. The particle size can be controlled in the range of 50 to $600 \mathrm{~nm}$ by varying polymer concentrations and molecular weights.

2. Increased polymer concentrations at particle preparation leads to a larger red shift of the corresponding colloidal dispersions, suggesting that interchain interaction would be stronger as the concentration became higher.

3. P3HT in the dispersed state shows a thermochromic transition from ordered phase to quasi-ordered phase upon heating.

Received: May 16, 2007 Accepted: September 26, 2007 Published: November 13, 2007

\section{REFERENCES}

1. J. Roncali, Chem. Rev., 92, 711 (1992).

2. S. D. D. V. Rughooputh, S. Hotta, A. J. Heeger, and F. Wudl, J. Polym. Sci., Polym. Phys., 25, 1071 (1987).

3. O. Inganas, W. R. Salaneck, J.-E. Osterholm, and J. Laakso, Synth. Met., 22, 395 (1988).

4. C. A. Sandstedt, R. D. Rieke, and C. J. Eckhardt, Chem. Mater., 7, 1057 (1995).

5. K. Faid, M. Frechette, M. Ranger, L. Mazerolle, I. Levesque, M. Leclerc, T.-A. Chen, and R. D. Rieke, Chem. Mater., 7, 1390 (1995).

6. C. Yang, F. P. Orfino, and S. Holdcroft, Macromolecules, 29, 6510 (1996).

7. M. Surin, Ph. Leclere, R. Lazzaroni, J. D. Yuen, G. Wang, D. Moses, A. J. Heeger, S. Cho, and K. Lee, J. Appl. Phys., 100, 33712 (2006),

8. W. U. Huynh, J. J. Dittmer, and A. P. Alivisatos, Science, 295, 2425 (2002).

9. J. Matsui, S. Yoshida, T. Mikayama, A. Aoki, and T. Miyashita, Langmuir, 21, 5343 (2005).

10. "Colloids and Colloid Assemblies," F. Caruso, Ed., Wiley-VCH, Weinheim, 2004.

11. "Chemistry and Technology of Emulsion Polymerisation," A. M. van Herk, Ed., Blackwell Publishing, Oxford, 2005.

12. T. Yamamoto, D. Komarudin, M. Arai, B.-L. Lee, H. Suganuma, N. Asakawa, Y. Inoue, K. Kubota, S. Sasaki, T. Fukuda, and H. Matsuda, J. Am. Chem. Soc., 120, 2047 (1998).

13. T. Yamamoto, D. Komarudin, K. Kubota, and S. Sasaki, Chem. Lett., 235 (1998).

14. H. Takeuchi and M. Kobashi, Chem. Lett., 415 (1999).

15. A. Fraleoni-Morgera, S. Marazzita, D. Frascaro, and L. Setti, Synth. Met., 147, 149 (2004).

16. R. Sugimoto, S. Takeda, H. B. Gu, and K. Yoshino, Chem. Express, 1, 635 (1986).

17. Y. Kaneko, S. Shimada, T. Fukuda, T. Kimura, H. Yokoi, H. Matsuda, T. Onodera, H. Kasai, S. Okada, H. Oikawa, and H. Nakanishi, Adv. Mater., 17, 160 (2005).

18. P. Calvo, B. Gouritin, H. Chacun, D. Desmaele, J. D'Angelo, J.-P Noel, D. Georgin, E. Fattal, J. P. Andreux, and P. Couvreur, Pharm. Res., 18, 1157 (2001).

19. M. Kobashi and H. Takeuchi, Macromolecules, 31, 7273 (1998).

20. K. Tashiro, Y. Minagawa, M. Kobayashi, S. Morita, T. Kawai, and K. Yoshino, Synth. Met., 55, 321 (1993). 